Tohoku J. exp. Med., 1980, 130, 129-137

\title{
Radioimmunoassay of Neurotensin and the Distribution and Concentration of Gut Neurotensin in Rat and Dog
}

\author{
Yoichi Iwasaki, Seiki Ito and Akira Shibata \\ The First Department of Internal Medicine, Niigata University \\ School of Medicine, Niigata 951
}

Iwasaki, Y., Ito, S. and Shibata, A. Radioimmunocissay of Neurotensin and the Distribution and Concentration of Gut Neurotensin in Rat and Dog. Tohoku J. exp. Med., 1980, 130 (2), 129-137—A specific radioimmunoassay (RIA) for neurotensin (NT) has been developed. Four antisera of high avidity were raised in 4 rabbits immunized with synthetic NT tridecapeptide coupled with bovine serum albumin via glutaraldehyde. NT was labeled with $\mathrm{Na}{ }^{125} \mathrm{I}$ by means of modified Hunter-Greenwood's chloramine-T method. Sensitivity of the RIA was $100 \mathrm{pg} /$ ml. Cross-reactivity of antiserum to other peptides was not observed. Using the RIA, the distribution and concentration of gastrointestinal (GI)-NT have been determined in acid-acetone extracts of rat and dog GI tissues. RIA using four kinds of antisera similarly detected higher concentrations in jejuno-ileal sections than in other regions. Although the distribution of GI-NT was quite similar between rat and dog, its concentration showed species specific difference. - neurotensin; radioimmunoassay; gastrointestinal tissue

Neurotensin (NT) is a tridecapeptide (MW 1674) with kinin mimetic actions (Carraway and Leeman 1973, 1975a). This peptide was isolated from bovine hypothalamic extracts by Carraway and Leeman in 1973. Increasing evidence suggests that NT has a wide spectrum of pharmacological actions causing hypotension, vasodilatation, cyanosis, increased vascular permeability (Carraway and Leeman 1973; Rosell et al. 1976), gut contraction (Carraway et al. 1973), inhibition of gastric acid secretion (Andersson et al. 1976), hyperglycemia, hypoinsulinemia, hyperglucagonemia (Carraway et al. 1973; Carraway and Leeman 1976a; Brown and Vale 1976; Nagai and Frohman 1976) and release of several pituitary hormones, namely ACTH (Carraway 1972), growth hormone, prolactin (Rivier et al. 1977), LH and FSH (Makino et al. 1973). But physiological roles of this peptide remain obscure, since these effects of NT were observed after infusion of exogenous NT.

Establishment of radioimmunoassay (RIA) for NT clarified that this peptide was distributed not only throughout the central nervous system but also in the gut, and that the latter in the rat contained more than $85 \%$ of the total body NT (Carraway and Leeman 1976b; Kitabgi et al. 1976).

The observed manifold pharmacological actions of this peptide and its specific

Received for publication, December 26, 1978. 
distribution suggest that NT would play an important role in gastrointestinal (GI) functions.

In this paper, we report our RIA of NT and the distribution and content of NT in GI tissues of rat and dog.

\section{Materials and Methods}

Immunogen preparation. $4 \mathrm{mg}$ of NT (Protein Research Foundation, Osaka, Japan), $4 \mathrm{mg}$ of bovine serum albumin (BSA) and $0.1 \mathrm{ml}$ of $1 \%$ glutaraldehyde were dissolved

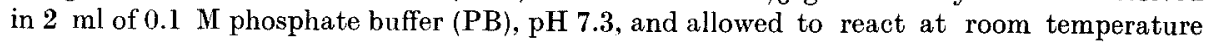
for $2 \mathrm{hr}$ and thereafter dialyzed against $1000 \mathrm{ml}$ of PB.

Immunization. To this dialyzed solution was added complete Freund's adjuvant and then the mixture was emulsified. This suspension was injected subcutaneously into the inner thighs of four New Zealand white rabbits. Immunization was repeated after 4 weeks. After 2 injections with NT-BSA conjugate, unconjugated NT emulsified with complete Freund's adjuvant was injected. Blood was drawn by ear eutting 10 days after the third immunization.

Preparation and purification of ${ }^{125}$ I-labeled NT. Synthetic NT tridecapeptide (Protein Research Foundation, Osaka, Japan) was labeled by modified Hunter-Greenwood's chloramine-T method (Hunter and Greenwood 1962) as follows: $2.5 \mu \mathrm{g}$ of NT dissolved in $20 \mu \mathrm{l}$ of $0.6 \mathrm{M} \mathrm{PB}(\mathrm{pH} 7.6), 500 \mu \mathrm{Ci}$ of $\mathrm{Na}^{125} \mathrm{I}$ and $6 \mu \mathrm{g}$ of chloramine-T dissolved

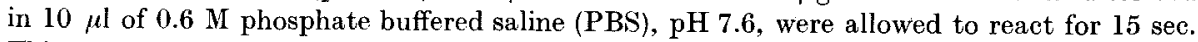
This reaction was terminated by adding $200 \mu \mathrm{g}$ of metabisulfate dissolved in $0.6 \mathrm{M}$ PBS (pH 7.6). This reaction mixture was purified by affinity chromatography or ion exchange chromatography as described by Carraway and Leeman (1976a). Damaged ${ }^{125} \mathrm{I}-\mathrm{NT}$ was checked according to the same procedure described in "RIA procedure", but at this time no antibody was added. Antigenicity of the purified ${ }^{125} \mathrm{I}$-NT was checked also with the same procedure, but at this time highly concentrated antibody was mixed.

$R I A$ procedure. The diluent for reagent was $0.05 \mathrm{M} \mathrm{PBS}(\mathrm{pH} 7.6)$. To each disposable plastic tube were added 1,000 units of trasylol, $300 \mu \mathrm{l}$ of ${ }^{125} \mathrm{I}-\mathrm{NT}, 300 \mu \mathrm{l}$ of appropriately diluted antiserum, and $200 \mu \mathrm{l}$ of standard NT solution in a dose range from $39 \mathrm{pg}$ to $2.5 \mathrm{ng}$ or unknown sample. The reaction mixture was incubated at $4^{\circ} \mathrm{C}$ for $72 \mathrm{hr}$ and thereafter bound and free hormones were separated by dextran coated charcoal method (Herbert et al. 1965).

Specificity. Specificity of antiserum was evaluated by the determination of crossreaction with $1 \mu \mathrm{g}$ of ACTH (Shionogi Seiyaku Co. Ltd.), $80 \mathrm{ng}$ of growth hormone (Dinabot Co. Ltd.), $80 \mathrm{ng}$ of prolactin (Daiichi radioisotope laboratory Co. Ltd.), $50 \mathrm{ng}$ of LH and FSH (Daiichi radioisotope laboratory Co. Ltd.), $100 \mathrm{pg}$ of ADH and oxytocin (Protein Reseach Foundation, Osaka, Japan), $1 \mu \mathrm{g}$ of substance P, somatostatin (Protein Research Foundation, Osaka, Japan), LH-RH (Tanabe Seiyaku Co. Ltd.), TRH (Takeda Seiyaku Co. Ltd.), glucagon (Lilly Co. Ltd.) and $80 \mu \mathrm{U}$ of insulin (Shimizu Seiyaku Co. Ltd.).

Accuracy. The accuracy of the RIA method was determined by measuring the recovery of known amounts of synthetic NT added to $100 \mu \mathrm{l}$ of dextran coated charcoal treated plasma or normal pooled plasma.

Precision. The precision of the RIA method was estimated by replicate determinations of NT concentrations in $200 \mu$ laliquots of a normal or pooled plasma measured in the same assay and in different assays.

Non-specific reactions due to trasylol and heparin were checked by addition of each anticoagulant in varying concentrations to the incubation mixtures.

Tissue extraction procedures. Rats were killed by decapitation and dogs were slaughtered by injection of a KCl solution of high concentration into the cardiac cavity. GI parts of these animals were extracted by acid acetone procedure as follows: Tissues were homogenized by a grinder and extracted for $24 \mathrm{hr}$ at $4^{\circ} \mathrm{C}$ with 5 volumes of a mixture of 
$1 \mathrm{~N} \mathrm{HCl}$ and acetone $(3: 100)$. After centrifugation of this mixture, the supernatant was mixed well with petroleum ether and acetone was evaporated in a warm bath at $70-80^{\circ} \mathrm{C}$. Residual fluid was lyophilized and used as the sample.

\section{Results}

Non-specific binding (Damage) of ${ }^{125}$ I-labeled NT purified by affinity chromatography or ion exchange chromatography to dextran coated charcoal was within $5 \%$ and its antigenicity was above $95 \%$. The purified ${ }^{125}$ I-labeled NT (Fig. 1) was quite stable for several weeks.

Fig. 2 shows a typical standard curve for NT and cross-reactivity of anti-NT antiserum to other peptides. The diluted antiserum recorded a $10 \%$ fall in binding from zero condition with the addition of $100 \mathrm{pg} / \mathrm{ml}$ of $\mathrm{NT}$, so the

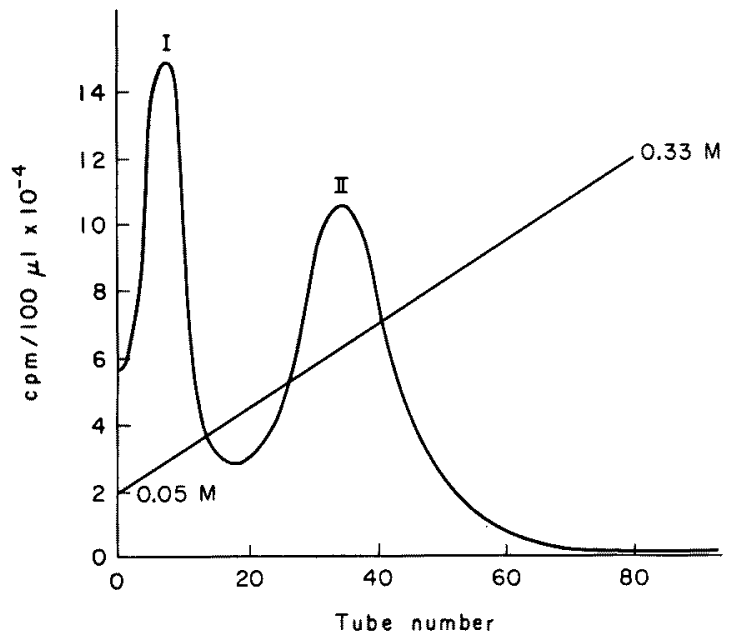

Fig. 1. Separation of ${ }^{125} \mathrm{I}$-neurotensin from free ${ }^{125} \mathrm{I}$ on sulfopropyl-Sephadex $\mathrm{C}-25$ column chromatography by linear gradient elution with $0.05 \mathrm{M}$ pyridine acetate in mixing chamber and $0.03 \mathrm{M}$ pyridine acetate in the reservoir. Peak I contained labeled products with little immunoreactivity. Peak II contained labeled products with greatest immunoreactivity.

minimum detectable amount of NT in this assay system was $100 \mathrm{pg} / \mathrm{ml}$. The antiserum showed no cross-reactivity to other peptides.

Fig. 3 shows the relationship between the amounts of synthetic NT added and recovered. Percent of recovery ranged from 87 to 110 . This relationship was obtained at a concentration of NT as high as $1250 \mathrm{pg} / \mathrm{ml}$.

The intra-assay and inter-assay variances are shown in Table 1. The precision expressed as coefficient of variance was $4.7 \%$ for intra-assay and $11.5 \%$ for inter-assay.

Heparin and trasylol at concentrations less than 10 units/ml and 1000 units/ $\mathrm{ml}$ respectively did not inhibit the binding of synthetic NT to the antiserum. (Fig. 4) 


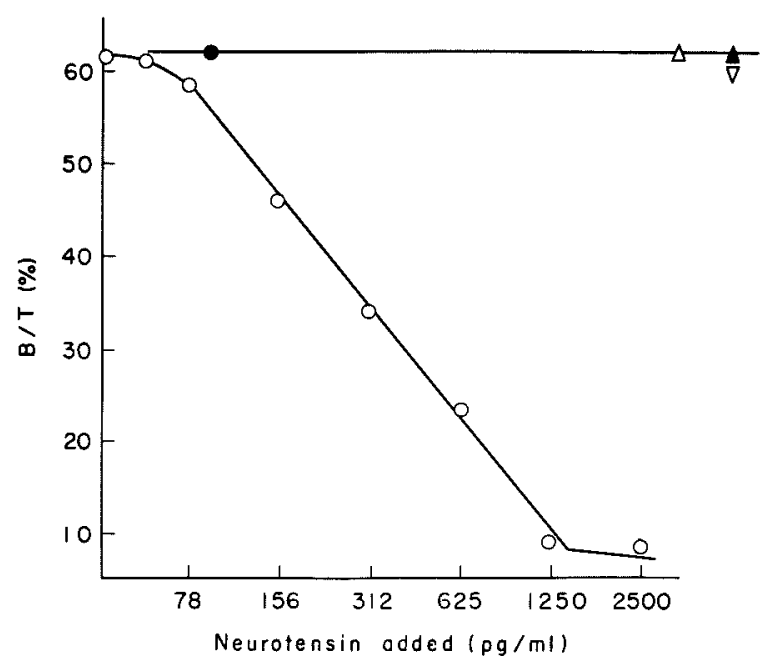

Fig. 2. Dose-response curve of radioimmunoassay for neurotensin (0-0) and lack of crossreactivity with other peptides described below.

$B$, bound radioactivity with anitserum; $T$, total of bound and free radioactivities;

•, ADH, oxytocin; $\triangle$, ACTH, GH, LH, FSH, PRL; $\Delta$, TSH; $\nabla$, substance-P, GIH,

LHRH, TRH, insulin, glucagon.

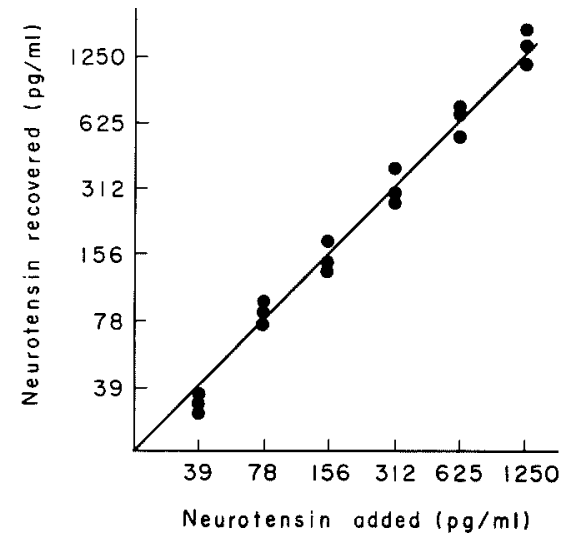

Fig. 3.

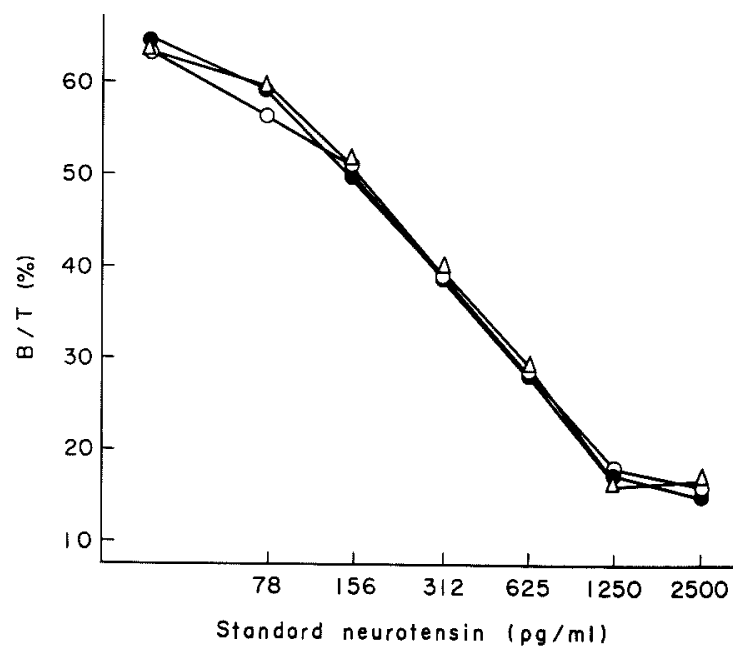

Fig. 4.

Fig. 3. Relationship between amounts of neurotensin added to and recovered from plasma.

Fig. 4. Comparison of inhibition curves of radioimmunoassay for neurotensin obtained by using trasylol, heparin, and anticoagulant free media, respectively. - - , without anticoagulant; $\bigcirc-0$, with trasylol; $\Delta-\Delta$, with heparin.

Figs. 5, 6, 7 and 8 show the dose response curves of synthetic NT in each RIA system using 4 kinds of antisera and dilution lines of rat GI extracts at the same time. Although minor differences were observed in each system, dilution lines of GI extracts fell in parallel with that of standard NT. This result convinced us 
TABLE 1. Intra- and inter-assay precision of the radioimmunoassay

\begin{tabular}{llccc}
\hline & \multicolumn{1}{c}{ Sample } & $\begin{array}{c}\text { Mean } \pm \text { s.D. } \\
(\mathrm{pg} / \mathrm{ml})\end{array}$ & $\begin{array}{c}\text { Coefficient of } \\
\text { variation }(\%)\end{array}$ & $N$ \\
\hline \multirow{3}{*}{ Intra-assay } & Normal plasma & $\mathbf{2 2 6 . 2 \pm 1 4 . 6}$ & 6.2 & 12 \\
& High plasma & $466.2 \pm 14.7$ & 3.1 & 13 \\
\multirow{2}{*}{ Inter-assay } & Normal plasma & $137.5 \pm 21.3$ & 15.1 & 12 \\
& High plasma & $327.0 \pm 28.9$ & 7.8 & 12 \\
\hline
\end{tabular}

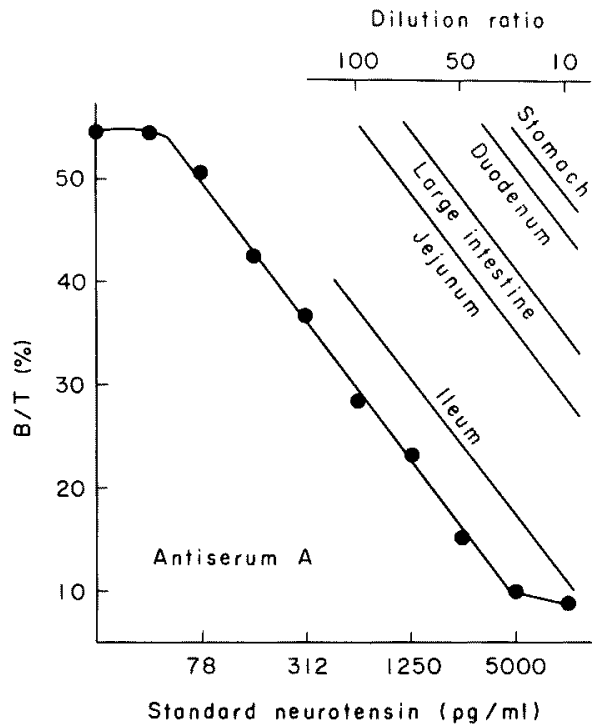

Fig. 5.

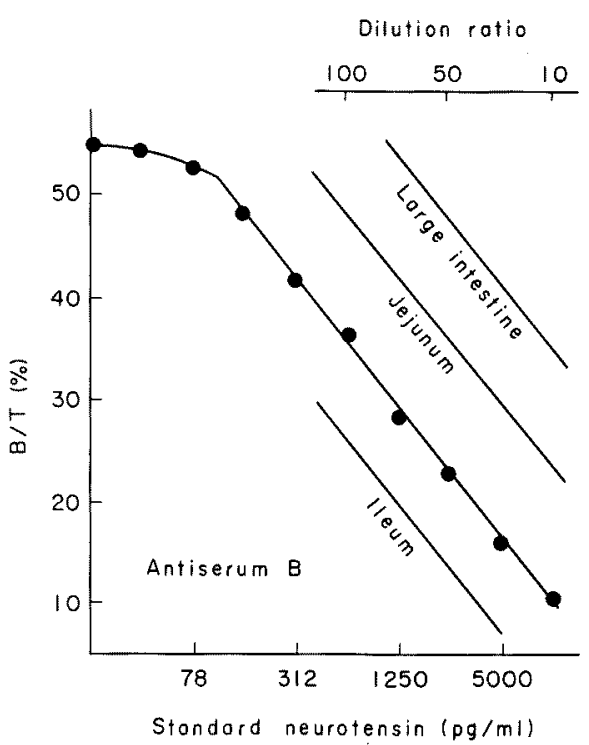

Fig. 6.

Fig. 5. Comparison of the dose-response curves made with extracts of rat gastrointestinal tissues with that of synthetic neurotensin.

At the upper right scale, the dilution ratio of rat gastro-intestinal extracts is indicated. Minimum detectable level of this radioimmunoassay system (using antiserum A) was $100 \mathrm{pg} / \mathrm{ml}$. This antiserum detected the neurotensin extracted from every section of gastrointestinal tract.

Fig. 6. Sensitivity of this antiserum was $100 \mathrm{pg} / \mathrm{ml}$. Although it detected the neurotensin only in jejuno-ileal and large intestinal tissues, the content of ileal neurotensin was the highest among 4 antisera.

that these tissues in the rat contained a substance immunologically indistinguishable from NT tridecapeptide.

Table 2 shows the concentration of rat GI-NT measured using 4 kinds of antisera. Although individual antisera detected rat GI-NT showing slightly different behaviors each other the result obtained revealed that the distribution of GI-NT as estimated by using different antisera was almost similar, the highest value in the ileum, the second in the jejunum, the third in the large intestine and only traces in the gastro-duodenal area.

Table 3 shows the concentration and the distribution of rat and canine GI-NT measured by antiserum C. In these two animals, almost $95 \%$ of the total GI-NT 


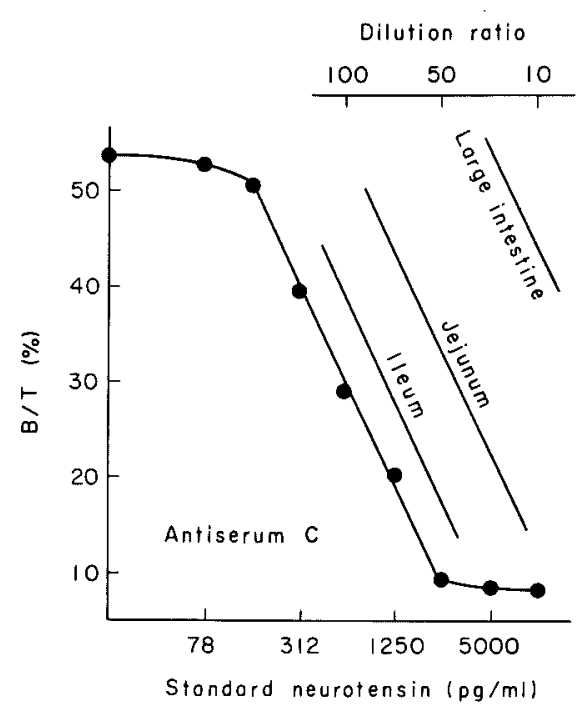

Fig. 7 .

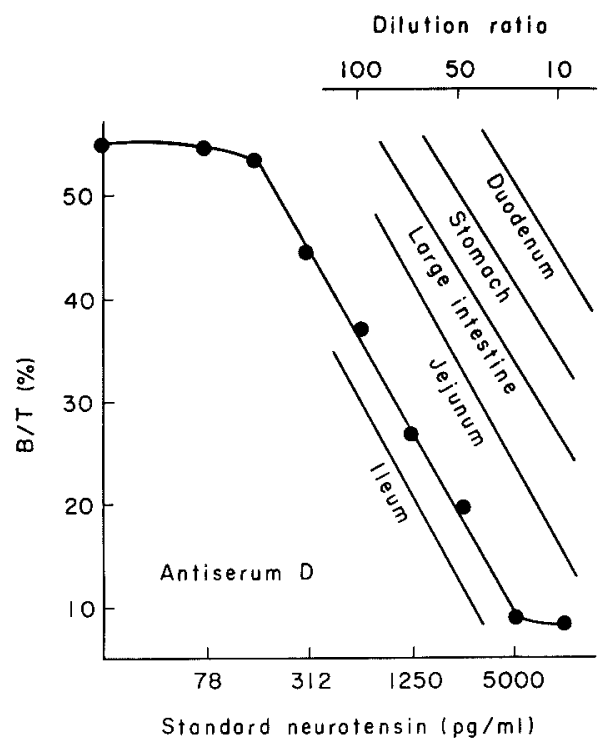

Fig. 8.

Fig. 7. Sensitivity of this assay system was almost $200 \mathrm{pg} / \mathrm{ml}$. Antiserum C, determined only lower intestinal neurotensin in the same way as antiserum B. But ileal neurotensin was not so high when estimated in this system.

Fig. 8. Minimum detectable neurotensin using antiserum $D$ was about $250 \mathrm{pg} / \mathrm{ml}$. But values of neurotensin in various gastrointestinal tissues detected with this antiserum were relatively higher as compared with those obtained with antiserum $A$.

TABLE 2. Distribution and concentration of rat gastrointestinal neurotensin (NT) using 4 antisera

\begin{tabular}{lrrrr}
\hline \multirow{2}{*}{ Tissue $(N)$} & \multicolumn{5}{c}{ NT (ng/g t.w.) } \\
\cline { 2 - 3 } \cline { 4 - 5 } & Ant. A & Ant. B & Ant. C & Ant. D \\
\hline Stomach (9) & 2.1 & n.d. & n.d. & 13.2 \\
Duodenum (9) & 3.4 & n.d. & n.d. & 6.5 \\
Jejunum (9) & 10.3 & 36.7 & 22.3 & 42.1 \\
Ileum (9) & 47.9 & 130.9 & 78.5 & 126.4 \\
Large intestine (9) & 5.1 & 10.5 & 5.2 & 11.1 \\
\hline
\end{tabular}

t.w., tissue weight; n.d., not detected.

TABLE 3. Comparison of gastrointestinal neurotensin (NT) between rat and dog using antiserum $C$

\begin{tabular}{lccccc}
\multirow{2}{*}{ Tissue } & \multicolumn{2}{c}{ Rat $(N=9)$} & & \multicolumn{2}{c}{$\operatorname{Dog}(N=3)$} \\
\cline { 2 - 3 } & NT (ng/g t.w.) & $\%$ & & NT (ng/g t.w.) & $\%$ \\
\hline Stomach & n.d. & 0 & & n.d. & 0 \\
Duodenum & n.d. & 0 & & 100.4 & 5.2 \\
Jejunum & $\mathbf{2 2 . 3}$ & $\mathbf{2 1 . 0}$ & $\mathbf{4 2 0 . 6}$ & $\mathbf{2 1 . 8}$ \\
Ileum & $\mathbf{7 8 . 5}$ & $\mathbf{7 4 . 1}$ & 1395.5 & $\mathbf{7 2 . 5}$ \\
Large intestine & $\mathbf{5 . 2}$ & 4.9 & 9.0 & 0.5 \\
\hline
\end{tabular}

t.w., tissue weight; n.d., not detected. 
was contained in the jejuno-ileal tissues and residual small percentages in other regions. Another matter of interest is that the concentration of NT in canine jejuno-ileal tissues was 18 times higher than those in rat and that no difference was recognized in the large intestine and upper digestive tissues.

\section{Discussion}

It has been noted that production of antibodies to small peptides is difficult unless its antigenicity is enhanced by coupling with a larger molecule. Although $\mathrm{NT}$ is a small peptide (MW 1674), we succeeded in raising 4 sensitive anti-NT antisera in all four rabbits by initial two injections of NT-BSA conjugates and thereafter one booster with unconjugated NT. From this result, it is clear that the peptide-antiserum producing system which has already been stimulated by the two injections of BSA-conjugated peptide are highly sensitive to the immunization with the unconjugated NT. Therefore, our modified immunizing procedure seems to be recommendable for production of antisera against small molecular peptides.

The original RIA for NT was recently published by Carraway and Leeman (1976a). They raised antisera in rabbits immunized with NT linked to poly (Glu Lys) and hemocyanine via 1-ethyl-(3-dimethyl-aminopropyl)-carbodiimide- $\mathrm{HCl}$. Their antisera were classified into three different types; the first reacted exclusively toward the COOH-terminal 4 to 6 amino acids in NT that lost almost all hyperglycemic effect, the second toward the 8 amino acids, and the third toward entire NT tridecapeptide sequence. Further they reported that RIA using the first antiserum revealed the highest concentration of NT in gastroduodenal regions, while RIA using the second and third antisera showed the highest concentration in the jejuno-ileal tissues. (Carraway and Leeman 1976b)

In our experiment, each RIA using 4 kinds of antisera detected only traces of NT in the rat and dog gastro-duodenal regions with the highest in the jejuno-ileal tissues. It is therefore speculated that our antibodies were raised toward the total amino acid sequence of NT or more than eight amino acid sequence possessing biological actions, similer to the second or third type of antiserum obtained by Carraway and Leeman. Further investigation using multiple fragments and analogues of NT was not attempted in our stndy.

The distribution and concentration of GI-NT determined separately with our 4 kinds of antisera were almost similar. This immunological similarity of our antisera seems to be due to the same course of immunization and immunogen preparation procedures.

As shown in Table 3, the content of NT was highest in the jejuno-ileal regions in the rat and dog. On the other hand, several immunohistochemical investigations have also confirmed that discrete endocrine cells reacting with anti-NT antisera are located in the lower intestine in the dog, human and rabbit (Orci et al. 1976; Sundler et al. 1977). This characteristic distribution of NT in the GI tract and high concentration of NT in the ileum suggest that NT may play particular roles in the lower GI functions. 
It was noticed that the content of NT in the dog jejuno-ileal tissues was about 18 times higher than that in the rat, whereas in other GI tissues the content of NT was not so much different between the two animals. These results suggest that the functional significance of NT in the GI tract may be different from species to species.

An increasing number of findings have made it clear that another kinin-like active undecapeptide (substance $\mathrm{P}$ ) and vasoactive 28 amino acid peptide (VIP) also share dual localization in both intra-cranial and GI tissues (Polak et al. 1974; Pearse and Polak 1975; Bryant et al. 1976; Larsson et al. 1976). In contrast to the GI distribution of these two peptides, for example, the former peptide is mainly distributed in the duodeno-jejunal and large intestinal regions (Nilsson et al. 1975) and the latter in the duodenum and ileo-colonal sections (Polak et al. 1974; Bloom et al. 1975; Said and Rosenberg 1976; Buffa et al. 1977). In our experiment using the rat and $\operatorname{dog}$ the concentration of NT was highest in the jejuno-ileal regions. This unique distribution of GI-NT suggests that physiological role of NT in GI function is different from that of other kinin mimetic polypeptides.

\section{References}

1) Andersson, S., Chang, D., Folkers, K. \& Rosell, S. (1976) Inhibition of gastric acid secretion in dogs by neurotensin. Life Sciences, 19, 367-370.

2) Bloom, S.R., Bryant, M.G. \& Polak, J.M. (1975) Distribution of gut hormones. Gut, 19, 821.

3) Brown, M. \& Vale, W. (1976) Effects of neurotensin and substance $P$ on plasma insulin, glucagon and glucose levels. Endocrinology, 98, 819-822.

4) Bryant, M.G., Polak, J.M., Modlin, I., Bloom, S.R., Pearse, A.G.E. \& Albuquerque, R.H. (1976) Possible dual role for vasoactive intestinal peptide as gastrointestinal hormone and neurotransmitter substance. Lancet, 1, 991--993.

5) Buffa, R., Capella, C., Solcia, E., Feigerio, B. \& Said, S.I. (1977) Vasoactive intestinal peptide (VIP) cells in the pancreas and gastrointestinal mucosa. Histochemistry, 50, 217-227.

6) Carraway, R.E. (1972) Ph. D. thesis, Department of Biochemistry, Brandeis University, University microfilms 72-32, 090p. 121-127, Ann. Arbor. Michigan.

7) Carraway, R. \& Leeman, S.E. (1973) The isolation of a new hypotensive peptide, neurotensin, from bovine hypothalami. $J$. biol. Chem., 249, 6854-6861.

8) Carraway, R. \& Leeman, S.E. (1975a) The amino acid sequence of a hypothalamic peptide, neurotensin. $J$. biol. Chem., 250, 1907-1911.

9) Carraway, R. \& Leeman, S.E. (1975b) The synthesis of neurotensin. J. biol. Chem., 250, 1912-1918.

10) Carraway, R. \& Leeman, S.E. (1976a) Radioimmunoassay for neurotensin, a hypothalamic peptide. $J$. biol. Chem., 251, 7035-7044.

11) Carraway, R. \& Leeman, S.E. $(1976 \mathrm{~b})$ Characterization of radioimmunoassayable neurotensin in the rat. J. biol. Chem., 251, 7045-7052.

12) Carraway, R., Demers, L. \& Leeman, S.E. (1973) Hyperglycemic effect of a hypothalamic peptide. Fed. Proc., 32, 211.

13) Herbert, V., Lau, K.-S., Gottlieb, C.W. \& Bieicher, S.J. (1965) Coated charcoal immunoassay of insulin. $J$. clin. Endocr., 25, 1375-1384.

14) Hunter, W.M. \& Greenwood, F.C. (1962) Preparation of iodine-131 labeled human growth hormone of high specific activity. Nature, 194, 495-496.

15) Kitabgi, P., Carraway, R. \& Leeman, S.E. (1976) Isolation of a tridecapeptide from 
bovine intestinal tissue and its partial characterization as neurotensin. $J$. biol. Chem., 251, 7053-7058.

16) Larsson, L.I., Fahrenkrug, J., Schaffalitzky de Muckadell, O., Sundler, F., Håkanson, R. \& Rehfeld, J.F. (1976) Localization of vasoactive intestinal polypeptide (VIP) to central and peripheral neurones. Proc. nat. Acad. Sci. USA, 73, 3197-3200.

17) Makino, T., Carraway, R., Leeman, S.E. \& Greep, R.O. (1973) Abstract, Society for the Study of Reproduction, Sixth Annual Meeting, Athens, Georgia, p. 26.

18) Nagai, K. \& Frohman, L.A. (1976) Hyperglycaemia and hyperglucagonemia follow. ing neurotensin administration. Life Sciences, 19, 273-280.

19) Nilsson, G., Larsson, L.-I., Hakanson, R., Brodin, E., Pernow, B. \& Sundler, F. (1975) Localization of substance P-like immunoreactivity in mouse gut. Histochemistry, 43, 97-99.

20) Orci, L., Baetens, O., Brown, M., Vale, W. \& Guillemin, R. (1976) Evidence for immunoreactive neurotensin in dog intestinal mucosa. Life Sciences, 19, 559-562.

21) Pearse, A.G.E. \& Polak, M. (1975) Immunocytochemical localization of substance P in mammalian intestine. Histochemistry, 41, 373-375.

22) Polak, J.M., Pearse, A.G.E., Garaud, J.C. \& Bloom, S.R. (1974) Cellular localization of vasoactive intestinal peptide in mammalian and avain gastrointestinal tract. Gut, 15, $720-724$

23) Rivier, C., Brown, M. \& Vale, W. (1977) Effects of neurotensin, substance P and morphine sulfate on the secretion of prolactin and growth hormone in the rat. Endocrinology, 100, 751-754.

24) Rosell, S., Burcher, E., Chang, D. \& Folkers, K. (1976) Cardiovascular and metabolic actions of neurotensin and (GIn)-neurotensin. Acta physiol. scand., 98, 484-491.

25) Said, S.I. \& Rosenberg, R.N. (1976) Vasoactive intestinal polypeptide: abundant immunoreactivity in neural cell lines and normal tissue. Science, 192, 907-908.

26) Sundler, F., Hakanson, R., Hammer, R.A., Alumet, J., Carraway, R., Leeman, S.E. \& Zimmerman, E. (1977) Immunohistochemical localization of neurotensin in endocrine cells of the gut. Cell Tissue Res., 178, 313-321. 